\title{
Assessment of bacterial contamination of toothbrushes using Illumina MiSeq
}

\author{
So Yeon Lee ${ }^{1,2}$, Si Young Lee ${ }^{1,2 *}$ \\ ${ }^{1}$ Department of Oral Microbiology, College of Dentistry, Gangneung-Wonju National University, Gangneung, Korea \\ ${ }^{2}$ Research Institute of Oral Science, Gangneung-Wonju National University, Gangneung, Korea
}

\begin{abstract}
Toothbrushes are commonly used to remove dental plaque, and the presence of bacteria on toothbrushes has been previously reported. Toothbrushes are contaminated by many bacteria after brushing, and contaminated toothbrushes can cause oral and systemic diseases. Toothbrush contamination was studied previously, but the study was limited because it only identified specific bacteria using a general bacterial culture method. To overcome this limitation, we used Illumina sequencing to identify microorganisms present on toothbrushes. Toothbrush samples were divided into two groups according to the storage location: a toothbrush stored in the office or a toothbrush in the bathroom. Samples were sequenced using Illumina sequencing. Enterococcus (30.76\%), Pseudomonas (21.85\%), Streptococcus (14.94\%), and Lactobacillus (5.15\%) were the predominant bacteria found on the toothbrushes stored in the office. Streptococcus (19.73\%), Pseudomonas (16.08\%), Enterococcus (8.16\%), and Neisseria (7.04\%) were the predominant species on the toothbrushes stored in the bathroom. In addition, $36.29 \%$ of the bacteria on the toothbrushes stored in the office and $33.77 \%$ of the bacteria on the toothbrushes stored in the bathroom were identified as potentially pathogenic bacteria. Both groups included microorganisms such as Streptococcus, Actinomyces, Porphyromonas, and Fusobacterium that are related to oral disease. This study confirmed the high contamination rate of used toothbrushes and demonstrated that repeated use of toothbrushes could lead to contamination by pathogenic bacteria.
\end{abstract}

Key Words: Bacteria, Bathroom, Dental plaque, Toothbrush

(c) This is an open-access article distributed under the terms of the Creative Commons Attribution Non-Commercial License (http://creativecommons.org/licenses/by-nc/4.0) which permits unrestricted noncommercial use, distribution, and reproduction in any medium, provided the original work is properly cited.

\section{INTRODUCTION}

Toothbrushes are generally used to remove dental plaque and some studies demonstrate the presence of bacteria on toothbrushes [1-3]. Many bacteria are found on toothbrushes after brushing [4], and these bacteria can survive for one day to one week after brushing [5]. Toothbrushes can be contaminated by the oral environment, hands, and contaminated containers [6]. Contaminated toothbrushes can cause oral disease, sepsis, and many systemic diseases of the cardiovascular system, respiratory organs, and the kidneys [7].

Various studies reported the number and types microorganisms present on toothbrushes and reported contamination by pathogenic microorganisms after using toothbrushes [8-13]. An average of $10^{3}$ to $10^{5}$ colony-forming unit (CFU) of bacteria were found per toothbrush. Malmberg et al. [10] examined the distribution of microorganisms in 44

Received May 10, 2019; Revised July 11, 2019; Accepted July 11, 2019

Corresponding author: Si Young Lee, Department of Oral Microbiology, College of Dentistry and Research Institute of Oral Science, Gangneung-Wonju National University, 7 Jukheon-gil, Gangneung 25457, Korea.

Tel: +82-33-640-2455, Fax: +82-33-642-6410, E-mail: siyoung@gwnu.ac.kr

Copyright $\odot$ 2019, Oral Biology Research Institute 
toothbrushes collected from four nurseries. Streptococci like Streptococcus salivarius, Streptococcus sanguinis, and Streptococcus mitis were most prevalent in these studies, and Haemophilus was found in $82 \%$ of the samples. Researchers also found oral microorganisms associated with periodontal disease and fungi. Another study found that $70 \%$ of toothbrushes were contaminated with pathogenic microorganisms after use [14].

Most of these studies used a method of culturing bacteria in a specific medium. The identified microorganisms were identified using Gram staining and biochemical characteristics. However, this identification method is limited because it cannot detect microorganism species that are not cultured. Sometimes, identification using biochemical properties may not match the characteristics of any known species or genus.

To overcome these limitations, this study used Illumina sequencing to identify microorganisms present on toothbrushes.

\section{MATERIALS AND METHODS}

\section{Sampling}

A total of 10 toothbrush samples were obtained by collecting 2 toothbrushes (group A; toothbrushes stored in the office, group B; toothbrushes stored in the bathroom) from 5 healthy adults (aged 20-50). The toothbrush sample was transferred to a test tube containing $10 \mathrm{~mL}$ of sterile distilled water and vortexed for 5 minutes to remove the bacteria from the head of toothbrush.

\section{Genomic DNA extraction}

The PureLink ${ }^{\circledR}$ Genomic DNA Mini Kit (Invitrogen, Waltham, MA, USA) was used to extract DNA from the 10 toothbrushes and DNA was extracted according to the manufacturer's instructions. For Illumina sequencing, individual DNA samples belonging to each group were mixed in equal proportions.

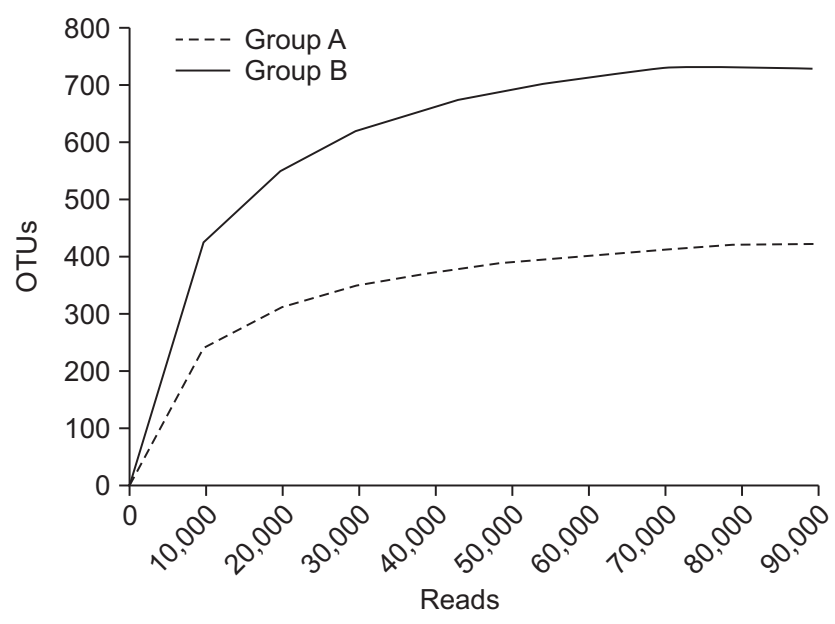

Fig. 1. Rarefaction curve of the bacterial communities in toothbrush samples. Group A, toothbrushes stored in the office; group B, toothbrushes stored in the bathroom; OTU, operational taxonomic units.

\section{Polymerase chain reaction amplification and Illumina sequencing}

For the metagenome analysis of extracted DNA samples, we used previously reported experimental methods $[15,16]$.

Rarefaction curve was shown in Fig. 1.

\section{Pathogenic bacteria analysis}

The bacterial genus was confirmed using Illumina sequencing analysis. The bacterial genera with evidence of pathogenicity in the last 10 years were identified using the PubMed database [17]. A species was deemed pathogenic if one of the bacteria belonging to the discovered bacterium genus was a species known to be pathogenic.

\section{RESULTS}

\section{Bacterial diversity of toothbrush samples}

Table 1 shows the microbial diversity of the two toothbrush groups with different storage locations (group A, group B). In group A, 78,171 reads and 126 genera were obtained, while 83,021 reads and 151 genera were obtained in group B. In group A, Enterococcus (30.76\%), Pseudomonas (21.85\%), Streptococcus (14.94\%) and Lactobacillus (5.15\%) were most abundant. In group B, Strep- 
Table 1. List of genera identified on toothbrushes using Illumina MiSeq

\begin{tabular}{|c|c|c|c|c|}
\hline \multirow{2}{*}{ Phylum } & \multirow{2}{*}{ Class } & \multirow{2}{*}{ Genus } & \multicolumn{2}{|c|}{ Count } \\
\hline & & & Group A & Group B \\
\hline \multicolumn{5}{|l|}{ Bacteria } \\
\hline \multirow[t]{19}{*}{ Actinobacteria } & Actinobacteria_c & Actinobaculum & 13 & 7 \\
\hline & & Actinomyces & 401 & 786 \\
\hline & & Antricoccus & - & 11 \\
\hline & & Arsenicicoccus & - & 11 \\
\hline & & Bifidobacterium & 282 & 403 \\
\hline & & Brachybacterium & - & 15 \\
\hline & & Brevibacterium & 131 & 218 \\
\hline & & Corynebacterium & 69 & 99 \\
\hline & & Dietzia & - & 4 \\
\hline & & Gardnerella & - & 7 \\
\hline & & Kocuria & 32 & 583 \\
\hline & & Microbacterium & 3 & - \\
\hline & & Phycicoccus & - & 2 \\
\hline & & Propionibacterium & 4 & 6 \\
\hline & & Rhodococcus & 3 & 70 \\
\hline & & Rothia & 1,557 & 2,908 \\
\hline & Coriobacteriia & Atopobium & 29 & 130 \\
\hline & & Collinsella & 9 & 14 \\
\hline & & Senegalimassilia & - & 8 \\
\hline \multirow[t]{14}{*}{ Bacteroidetes } & Bacteroidia & Alistipes & 58 & 890 \\
\hline & & Alloprevotella & 125 & 959 \\
\hline & & Bacteroides & - & 221 \\
\hline & & Dysgonomonas & 2 & - \\
\hline & & Marinifilum & 1 & - \\
\hline & & Parabacteroides & - & 20 \\
\hline & & Porphyromonas & 152 & 937 \\
\hline & & Prevotella & 861 & 3,813 \\
\hline & & Tannerella & 3 & 72 \\
\hline & Flavobacteria & Bergeyella & 17 & 88 \\
\hline & & Capnocytophaga & 81 & 162 \\
\hline & & Chryseobacterium & - & 14 \\
\hline & & Maritimimonas & - & 2 \\
\hline & Sphingobacteriia & Sphingobacterium & 5 & 140 \\
\hline Deinococcus-Thermus & Deinococci & Deinococcus & - & 102 \\
\hline \multirow[t]{16}{*}{ Firmicutes } & Bacilli & Aerococcus & - & 1 \\
\hline & & Alkalibacterium & 1 & - \\
\hline & & Bacillus & 55 & - \\
\hline & & Enterococcus & 24,088 & 6,790 \\
\hline & & Gemella & 232 & 1,994 \\
\hline & & Granulicatella & 205 & 309 \\
\hline & & Lactobacillus & 4,032 & 647 \\
\hline & & Lactococcus & 98 & 3 \\
\hline & & Staphylococcus & 64 & - \\
\hline & & Streptococcus & 11,703 & 16,410 \\
\hline & & Vagococcus & 1 & - \\
\hline & & Weissella & 7 & - \\
\hline & Clostridia & Acetatifactor & - & 7 \\
\hline & & Acidaminobacter & 81 & 3 \\
\hline & & Agathobacter & - & 4 \\
\hline & & Alkalibacter & 37 & - \\
\hline
\end{tabular}


Table 1. Continued

\begin{tabular}{|c|c|c|c|c|}
\hline \multirow{2}{*}{ Phylum } & \multirow{2}{*}{ Class } & \multirow{2}{*}{ Genus } & \multicolumn{2}{|c|}{ Count } \\
\hline & & & Group A & Group B \\
\hline & & Alkaliphilus & 31 & - \\
\hline & & Anaerovorax & 3 & - \\
\hline & & Blautia & 5 & 32 \\
\hline & & Butyricicoccus & - & 5 \\
\hline & & Caproiciproducens & - & 2 \\
\hline & & Catonella & 8 & 70 \\
\hline & & Clostridium & 12 & 129 \\
\hline & & Dorea & 7 & 13 \\
\hline & & Eisenbergiella & 23 & 597 \\
\hline & & Eubacterium & 42 & 210 \\
\hline & & Faecalibacterium & 6 & 64 \\
\hline & & Filifactor & - & 4 \\
\hline & & Fusicatenibacter & 6 & 10 \\
\hline & & Intestinibacter & 4 & - \\
\hline & & Lachnoanaerobaculum & 45 & 74 \\
\hline & & Lachnospira & - & 14 \\
\hline & & Marvinbryantia & - & 1 \\
\hline & & Mogibacterium & 1 & - \\
\hline & & Moryella & 45 & 69 \\
\hline & & Oribacterium & 57 & 73 \\
\hline & & Oscillibacter & 5 & 107 \\
\hline & & Peptostreptococcus & 25 & 190 \\
\hline & & Pseudoflavonifractor & 3 & 126 \\
\hline & & Romboutsia & 3 & 5 \\
\hline & & Roseburia & - & 6 \\
\hline & & Ruminococcus & 14 & 31 \\
\hline & & Sporobacter & - & 5 \\
\hline & & Subdoligranulum & - & 11 \\
\hline & & Tindallia & 11 & - \\
\hline & Erysipelotrichi & Bulleidia & 32 & 36 \\
\hline & & Catenibacterium & - & 14 \\
\hline & & Holdemanella & 2 & 6 \\
\hline & Negativicutes & Dialister & 2 & 12 \\
\hline & & Megamonas & - & 5 \\
\hline & & Megasphaera & 5 & 14 \\
\hline & & Pelosinus & 10 & 10 \\
\hline & & Phascolarctobacterium & - & 9 \\
\hline & & Selenomonas & 21 & 137 \\
\hline & & Veillonella & 1,261 & 3,757 \\
\hline & Tissierellia & Dethiosulfatibacter & 114 & - \\
\hline & & Parvimonas & 24 & 141 \\
\hline & & Tissierella & 157 & - \\
\hline \multirow[t]{3}{*}{ Fusobacteria } & Fusobacteria_c & Fusobacterium & 400 & 1,923 \\
\hline & & Leptotrichia & 111 & 893 \\
\hline & & Streptobacillus & - & 16 \\
\hline \multirow[t]{6}{*}{ Proteobacteria } & Alphaproteobacteria & Altererythrobacter & - & 7 \\
\hline & & Aureimonas & 13 & 15 \\
\hline & & Brevundimonas & 56 & 7 \\
\hline & & Novosphingobium & 5 & - \\
\hline & & Rhizobium & 467 & 18 \\
\hline & & Rhodobacter & - & 5 \\
\hline
\end{tabular}


Table 1. Continued

\begin{tabular}{|c|c|c|c|c|}
\hline \multirow{2}{*}{ Phylum } & \multirow{2}{*}{ Class } & \multirow{2}{*}{ Genus } & \multicolumn{2}{|c|}{ Count } \\
\hline & & & Group A & Group B \\
\hline & & Roseomonas & 18 & 2 \\
\hline & & Sphingobium & 8 & 5 \\
\hline & & Sphingomonas & 17 & 2 \\
\hline & Betaproteobacteria & Acidovorax & 13 & 13 \\
\hline & & Comamonas & 3 & 7 \\
\hline & & Curvibacter & 6 & 6 \\
\hline & & Dechloromonas & 29 & 18 \\
\hline & & Delftia & 61 & 35 \\
\hline & & Duganella & 3 & - \\
\hline & & Eikenella & - & 1 \\
\hline & & Herbaspirillum & 3 & - \\
\hline & & Janthinobacterium & 3,393 & 2,110 \\
\hline & & Kingella & 11 & 65 \\
\hline & & Lautropia & 23 & 198 \\
\hline & & Neisseria & 1,067 & 5,854 \\
\hline & & Paucibacter & 53 & 43 \\
\hline & & Simonsiella & - & 7 \\
\hline & & Sutterella & - & 4 \\
\hline & & Thauera & 2 & 1 \\
\hline & & Undibacterium & 6 & 11 \\
\hline & Deltaproteobacteria & Desulfonatronum & 194 & 10 \\
\hline & & Desulfovibrio & - & 7 \\
\hline & Epsilonproteobacteria & Arcobacter & - & 3 \\
\hline & & Campylobacter & 15 & 114 \\
\hline & & Helicobacter & - & 1 \\
\hline & & Sulfurovum & 2 & 3 \\
\hline & Gammaproteobacteria & Acinetobacter & 2,937 & 840 \\
\hline & & Actinobacillus & 3 & 101 \\
\hline & & Aeromonas & 389 & 264 \\
\hline & & Aggregatibacter & 7 & 122 \\
\hline & & Buttiauxella & 10 & 18 \\
\hline & & Cardiobacterium & 12 & 37 \\
\hline & & Cedecea & 68 & 36 \\
\hline & & Citrobacter & 27 & 12 \\
\hline & & Enhydrobacter & 195 & 332 \\
\hline & & Enterobacter & 458 & 129 \\
\hline & & Erwinia & 1,707 & 173 \\
\hline & & Escherichia & 43 & 11 \\
\hline & & Haemophilus & 556 & 2,047 \\
\hline & & Halomonas & 23 & 16 \\
\hline & & Halotalea & 3 & - \\
\hline & & Klebsiella & 5 & 156 \\
\hline & & Moraxella & - & 3 \\
\hline & & Morganella & 143 & 132 \\
\hline & & Pantoea & 133 & 4,109 \\
\hline & & Pseudoalteromonas & - & 1 \\
\hline & & Pseudomonas & 17,110 & 13,374 \\
\hline & & Rahnella & 15 & 5 \\
\hline & & Serratia & - & 8 \\
\hline & & Stenotrophomonas & 1,081 & 761 \\
\hline & & Vibrio & 2 & 8 \\
\hline
\end{tabular}


Table 1. Continued

\begin{tabular}{|c|c|c|c|c|}
\hline \multirow{2}{*}{ Phylum } & \multirow{2}{*}{ Class } & \multirow{2}{*}{ Genus } & \multicolumn{2}{|c|}{ Count } \\
\hline & & & Group A & Group B \\
\hline & & Woeseia & 2 & - \\
\hline & & Xanthomonas & - & 349 \\
\hline & & Yersinia & 54 & 15 \\
\hline Saccharibacteria_TM7 & Saccharimonas_c & Saccharimonas & 31 & 101 \\
\hline Spirochaetes & Spirochaetes_c & Treponema & 7 & 11 \\
\hline \multirow[t]{2}{*}{ Synergistetes } & Synergistia & Aminivibrio & 2 & - \\
\hline & & Fretibacterium & - & 6 \\
\hline Tenericutes & Mollicutes & Acholeplasma_g2 & 7 & 13 \\
\hline Verrucomicrobia & Verrucomicrobiae & Akkermansia & 4 & 95 \\
\hline Unknown & & & 732 & 3,473 \\
\hline Total & & & 78,171 & 83,021 \\
\hline
\end{tabular}

Group A, toothbrushes stored in the office; group B, toothbrushes stored in the bathroom; -, not available.

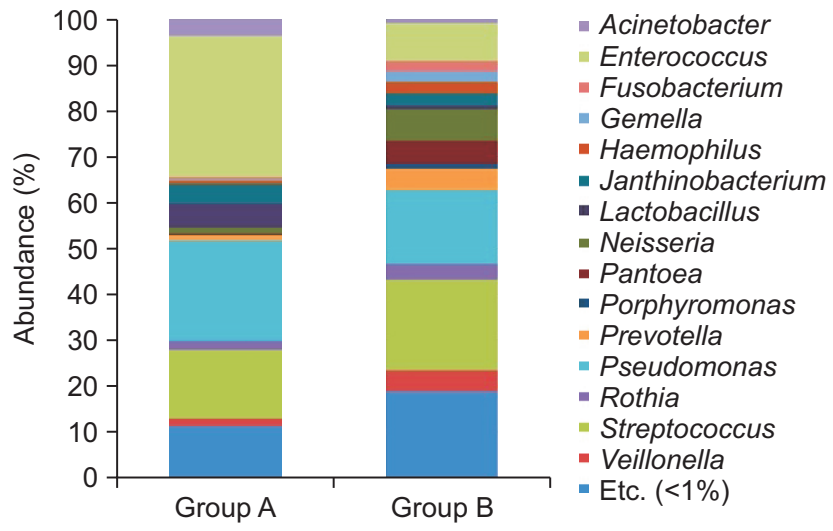

Fig. 2. Relative abundance of bacterial genera in toothbrush samples. Group A, toothbrushes stored in the office; group B, toothbrushes stored in the bathroom.

tococcus (19.73\%), Pseudomonas (16.08\%), Enterococcus (8.16\%) and Neisseria (7.04\%) were most abundant (Fig. $2-4)$.

\section{Pathogenic bacteria}

In group A, 45 out of 124 genera (36.29\%) belonged to pathogenic species. Enterococcus was the most common genus, and we also found pathogenic species in the genera Pseudomonas, Acinetobacter, Neisseria, Haemophilus, Corynebacterium, Staphylococcus, Bacillus, and Escherichia. We also detected bacteria associated with oral diseases like Streptococcus, Actinomyces, Fusobacterium, Porphyromonas, Treponema, Aggregatibacter, and Tannerella. In group
B, 51 genera out of 151 genera $(33.77 \%)$ contained pathogenic species. Streptococcus was the most common, and we also found pathogenic species such as Pseudomonas, Enterococcus, Neisseria, Haemophilus, Corynebacterium, Escherichia, and Helicobacter. We also found bacteria associated with oral diseases like Streptococcus, Fusobacterium, Porphyromonas, Actinomyces, Aggregatibacter, Tannerella, and Treponema.

\section{DISCUSSION}

The toothbrush is contaminated from the point of use, and the contamination increases when the toothbrush is used repeatedly [18,19]. In addition, $80 \%$ of toothbrushes are known to be contaminated before use [8]. The number of bacteria found on each toothbrush is highly variable and was reported to average from $10^{3}$ to $10^{5} \mathrm{CFU}$ per toothbrush $[8,10,12,13]$. Glass and Lare [19] examined the microbial distribution on toothbrushes used by adults and found various genera, including pathogenic species like Staphylococcus aureus, Escherichia coli, and Pseudomonas. In addition, Malmbeg et al. [10] investigated children's toothbrushes, finding mostly aerobic microorganisms and bacteria like Staphylococci and Pseudomonas, and fungi. In a study by Mehta et al. [14], 70\% of toothbrushes used in the experiment were found to be severely contaminated by pathogenic microorganisms. Studies on microbial contamination of toothbrushes have been done before, but most 


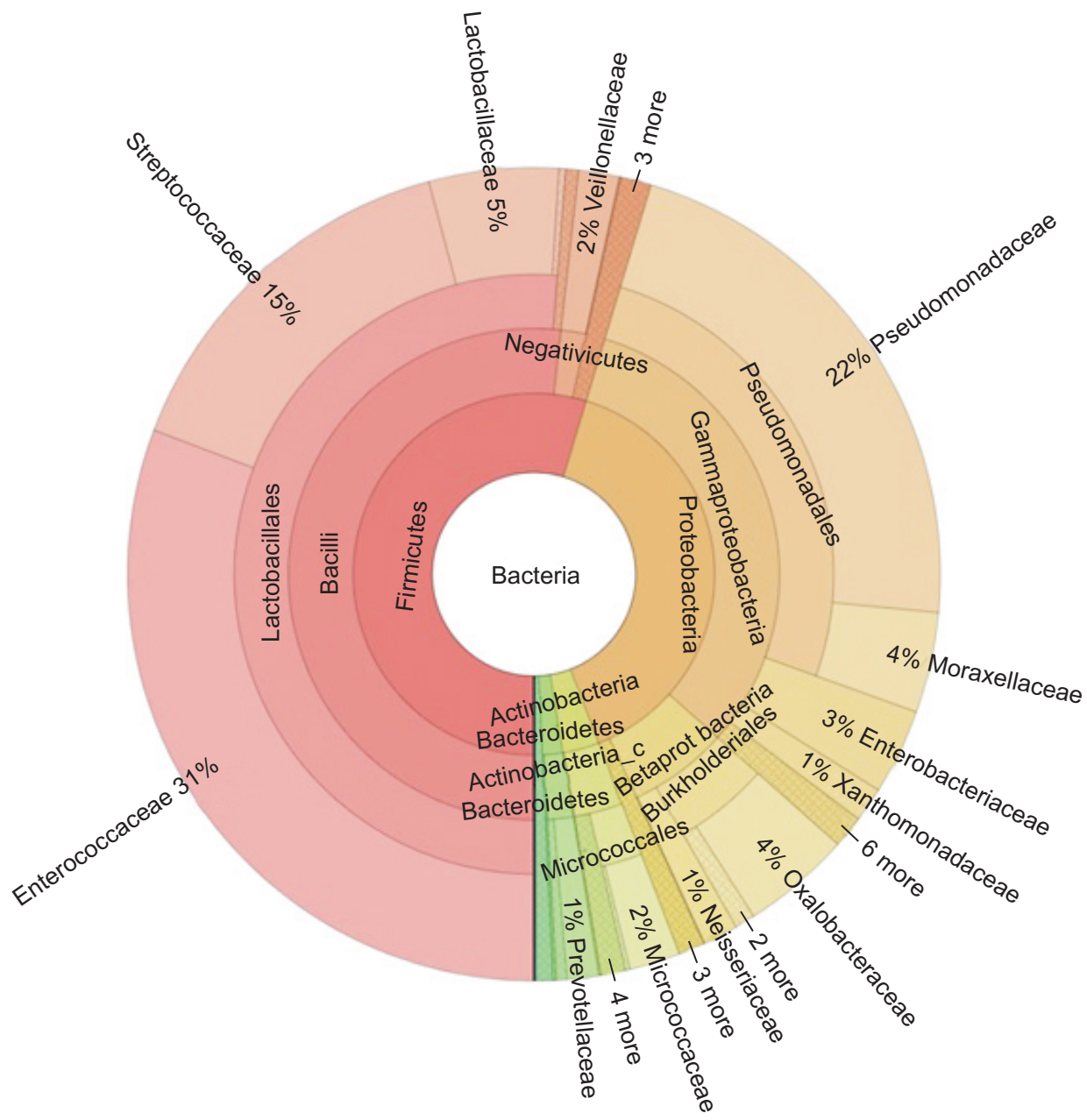

Fig. 3. Bacterial community diversity in toothbrush samples (group A, toothbrushes stored in the office). of them have identified bacteria based on general bacterial culture methods. Therefore, the risk of contaminated toothbrushes may be underestimated.

In our study, the Enterococcus genus known to have multi-drug resistance was found most frequently. We also found the genus Pseudomonas, an opportunistic infectious bacteria, and Streptococcus, a bacterium related to oral diseases. These results were similar to most other studies, but there were differences in the abundances found for each group. Among the toothbrushes stored in office, Enterococcus was observed at the highest abundance, followed by Pseudomonas, Streptococcus, and Lactobacillus. The Streptococcus genus was most frequently observed in toothbrushes stored in the bathroom, followed by Pseudomonas, Enterococcus, and Nisseria. The proportion of genera containing pathogenic species was observed to be $36.29 \%$ in group A and $33.77 \%$ in group B. In both groups, we found Haemophilus, which can cause a deadly respiratory infection, Corynebacterium, which is known to be the causative agent of diphtheria, and Neisseria, which can cause septicemia and gonorrhea. In group A, we found Bacillus and Staphylococcus. In group B, we found Helicobacter, which can cause stomach inflammation, gastric cancer, and peptic ulcer disease. In addition, we found several oral bacteria that are related to oral diseases. In both groups, we also found Streptococcus and Actinomyces, causative bacteria of dental caries, and Porphyromonas, Fusobacterium, Aggregatibacter, Tannerella, and Treponema, which are associated with periodontal disease.

Repeated use of contaminated toothbrushes may increase the possibility of bacterial infection [18]. We also found pathogenic bacteria that do not directly cause infection in healthy individuals but could be fatal to patients with weak immune systems. Thus, there is a need to reduce microbial 


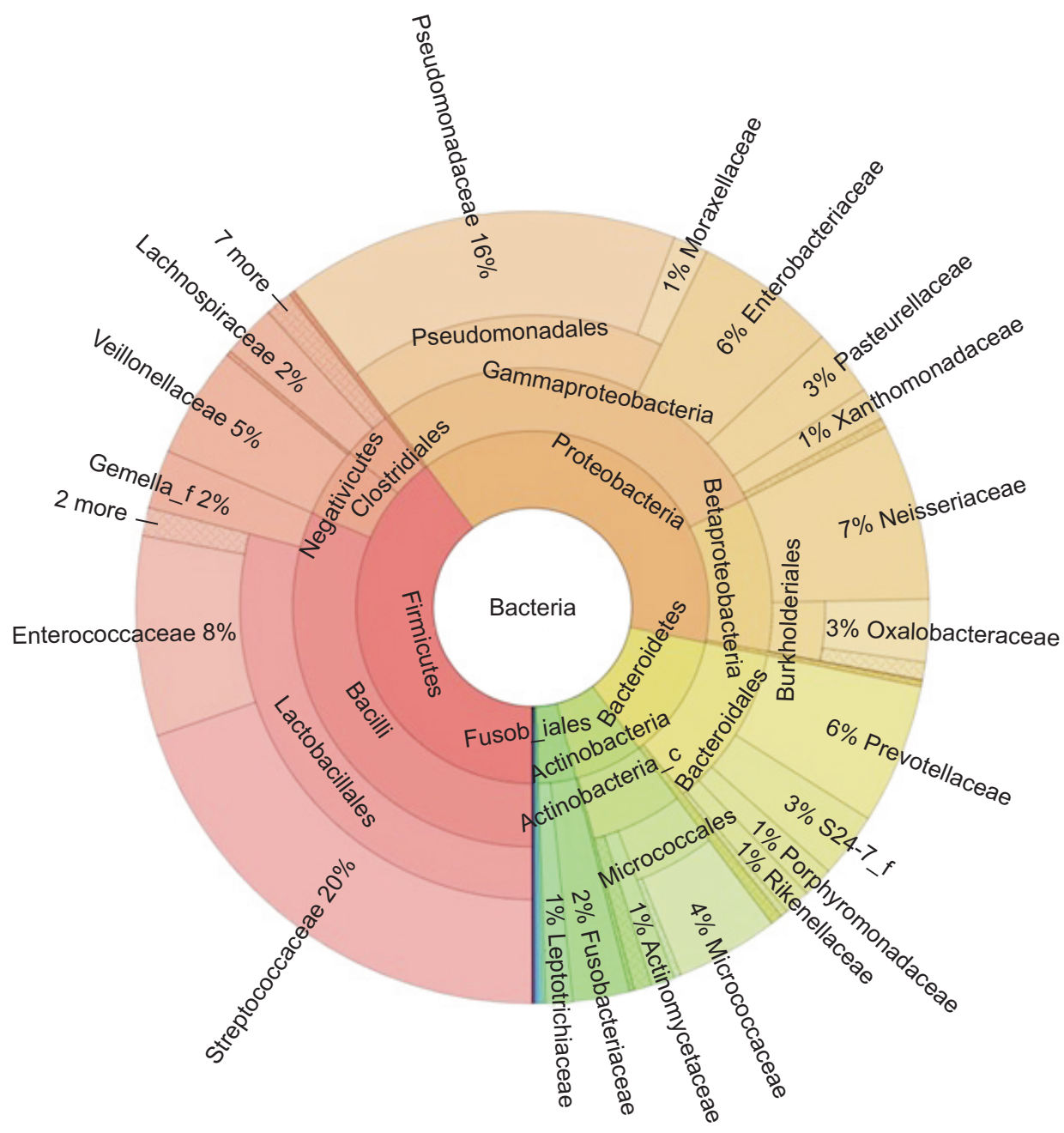

Fig. 4. Bacterial community diversity in toothbrush samples (group B, toothbrushes stored in the bathroom). contamination of toothbrushes. The contamination of the toothbrush can be influenced by factors like the shape of the toothbrush, the toothpaste, the storage of the toothbrush, the frequency of brushing, and the period of use. We obtained toothbrush samples in two groups according to storage location (group A, group B). Because toothbrushes are often stored in bathrooms, they can be exposed to enteric bacteria that are aerosolized [12]. We expected enteric bacteria to be found only in toothbrush samples stored in the bathroom, but enteric bacteria were isolated in both groups of toothbrushes. The toothbrush stored in the office seems to be contaminated with enteric bacteria via the human hand or other infection routes.

Based on previous studies, patients with systemic diseases are advised to frequently replace their toothbrush $[4,9,20]$. The American Dental Association recommends re- placing the toothbrush every three months [4], and patients with oral disease also reported reduced symptoms after replacing toothbrushes [9]. Many previous studies demonstrated that brushing is effective in improving oral hygiene $[21,22]$. There is also a risk of pathogenic microbial transfer due to toothbrush contamination and the positive role of such a toothbrush. Therefore, further research is needed to propose a method to reduce toothbrush contamination and establish better hygiene standards.

\section{CONFLICTS OF INTEREST}

The authors declare that they have no competing interests. 


\section{ORCID}

\author{
So Yeon Lee \\ https://orcid.org/0000-0002-6645-6831 \\ Si Young Lee \\ https://orcid.org/0000-0001-8826-1413
}

\section{REFERENCES}

1. Ho HP, Niederman R. Effectiveness of the Sonicare sonic toothbrush on reduction of plaque, gingivitis, probing pocket depth and subgingival bacteria in adolescent orthodontic patients. J Clin Dent 1997;8(1 Spec No):15-19.

2. Rosema NA, Timmerman MF, Versteeg PA, van Palenstein Helderman WH, Van der Velden U, Van der Weijden GA. Comparison of the use of different modes of mechanical oral hygiene in prevention of plaque and gingivitis. J Periodontol 2008;79:1386-1394. doi: 10.1902/ jop.2008.070654.

3. Creeth JE, Gallagher A, Sowinski J, Bowman J, Barrett K, Lowe S, Patel K, Bosma ML. The effect of brushing time and dentifrice on dental plaque removal in vivo. J Dent Hyg 2009;83:111-116.

4. Basman A, Peker I, Akca G, Alkurt MT, Sarikir C, Celik I. Evaluation of toothbrush disinfection via different methods. Braz Oral Res 2016;30:S1806-83242016000100203. doi: 10.1590/1807-3107BOR-2016.vol30.0006.

5. Efstratiou M, Papaioannou W, Nakou M, Ktenas E, Vrotsos IA, Panis V. Contamination of a toothbrush with antibacterial properties by oral microorganisms. J Dent 2007;35:331-337. doi: 10.1016/j.jdent.2006.10.007.

6. Frazelle MR, Munro CL. Toothbrush contamination: a review of the literature. Nurs Res Pract 2012;2012:420630. doi: $10.1155 / 2012 / 420630$.

7. Nascimento AP, Watanabe E, Ito IY. Toothbrush contamination by Candida spp. and efficacy of mouthrinse spray for their disinfection. Mycopathologia 2010;169:133-138. doi: 10.1007/s11046-009-9239-z.

8. Caudry SD, Klitorinos A, Chan EC. Contaminated toothbrushes and their disinfection. J Can Dent Assoc 1995; 61:511-516.

9. Glass RT, Jensen HG. More on the contaminated toothbrush: the viral story. Quintessence Int 1988;19:713-716.

10. Malmberg E, Birkhed D, Norvenius G, Norén JG, Dahlén G. Microorganisms on toothbrushes at daycare centers. Acta Odontol Scand 1994;52:93-98. doi:
10.3109/00016359409029061.

11. Müller HP, Lange DE, Müller RF. Actinobacillus actinomycetemcomitans contamination of toothbrushes from patients harbouring the organism. J Clin Periodontol 1989;16:388-390. doi: 10.1111/j.1600-051x.1989. tb00010.x.

12. Taji SS, Rogers AH. ADRF Trebitsch Scholarship. The microbial contamination of toothbrushes. A pilot study. Aust Dent J 1998;43:128-130. doi: 10.1111/j.1834-7819.1998. tb06101.x.

13. Verran J, Leahy-Gilmartin AA. Investigations into the microbial contamination of toothbrushes. Microbios 1996;85: 231-238.

14. Mehta A, Sequeira PS, Bhat G. Bacterial contamination and decontamination of toothbrushes after use. N Y State Dent J 2007;73:20-22.

15. Lee SY, Lee SY. Assessment of bacterial contamination of lipstick using pyrosequencing. J Cosmet Sci 2017;68:245252.

16. Kim JY, Kim EM, Yi MH, Lee J, Lee S, Hwang Y, Yong D, Sohn WM, Yong TS. Intestinal fluke Metagonimus yokogawai infection increases probiotic Lactobacillus in mouse cecum. Exp Parasitol 2018;193:45-50. doi: 10.1016/ j.exppara.2018.08.002.

17. Costa D, Mercier A, Gravouil K, Lesobre J, Delafont V, Bousseau A, Verdon J, Imbert C. Pyrosequencing analysis of bacterial diversity in dental unit waterlines. Water Res 2015;81:223-231. doi: 10.1016/j.watres.2015.05.065.

18. Bunetel L, Tricot-Doleux S, Agnani G, Bonnaure-Mallet $M$. In vitro evaluation of the retention of three species of pathogenic microorganisms by three different types of toothbrush. Oral Microbiol Immunol 2000;15:313-316. doi: 10.1034/j.1399-302x.2000.150508.x.

19. Glass RT, Lare MM. Toothbrush contamination: a potential health risk? Quintessence Int 1986;17:39-42. doi: 10.1016/0889-5406(87)90281-2.

20. Bhat SS, Hegde KS, George RM. Microbial contamination of tooth brushes and their decontamination. J Indian Soc Pedod Prev Dent 2003;21:108-112.

21. Dahlén G, Lindhe J, Sato K, Hanamura H, Okamoto H. The effect of supragingival plaque control on the subgingival microbiota in subjects with periodontal disease. J Clin Periodontol 1992;19:802-809. doi: 10.1111/j.1600-051x.1992. tb02174.x.

22. Axelsson P, Lindhe J, Nyström B. On the prevention of caries and periodontal disease. Results of a 15-year longitudinal study in adults. J Clin Periodontol 1991;18:182-189. doi: 10.1111/j.1600-051x.1991.tb01131.x. 